REALCOSTER: REAL COMMUNITY SERVICE CENTER JOURNAL

Volume 1, No. 2, September 2018 (38-45)

\title{
Edukasi Konstruktif Terhadap Fenomena LGBTQ Menurut Perspektif Teologi Kristen
}

\author{
Vicky BGD Paat ${ }^{1 *}$, Irfan Feriando Simanjuntak ${ }^{2}$, Harls Evan R. Siahaan ${ }^{3}$ \\ ${ }^{1,2}$ Prodi Teologi, STT REAL Batam \\ ${ }^{3}$ Prodi Teologi, STT Pelita Bangsa \\ vbgdpaat75@gmail.com
}

\begin{abstract}
:
LGBTQ is a fact of existence so it cannot be considered as an issue only. LGBTQ is not just a problem to be addressed so that it becomes a pro or con in society, including Christians, because LGBTQ is not a "rumor" or hearsay. LGBTQ is a fact or reality that exists in society. What is the Bible's answer about LGBTQ in 1 Corinthians 6:9-11, Paul states Don't be misguided! The fornicator, ... the adulteress, the effeminate, the sorcerer

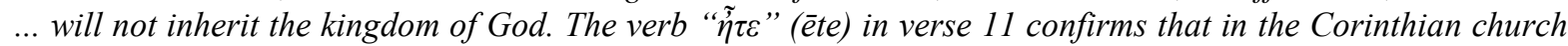

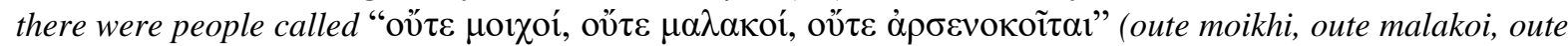

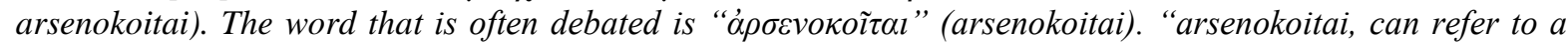
grown man who has a slave who is used as a sexual partner to fulfill his lust, so clearly this is a sin that requires church ministry as an expression of Christ's love that they need the true gospel that saves. Through this discussion I judge for us to return to the gospel which is the power of God that saves every believer! That is the gospel that makes the arsenokoitai give themselves to be sanctified and become people who are sanctified and justified in the name of the Lord Jesus Christ.
\end{abstract}

Keywords: LGBTQ, Christian Life, Christian Theology

\begin{abstract}
Abstrak
LGBTQ merupakan sebuah fakta keberadaannya sehingga tidak bisa dianggap sebagai sebuah isu saja. LGBTQ tidak sekedar sebuah masalah untuk ditanggapi sehingga menjadi pro atau kontra di masyarakat termasuk Kristen , karena LGBTQ bukan sebuah sebuah "desas-desus" atau kabar angina.. LGBTQ adalah sebuah sebuah fakta atau kenyataan yang ada di masyarakat. Apakah jawaban Alkitab tentang LGBTQ dalam 1 Korintus 6:9-11, Paulus menyatakan Janganlah sesat! Orang cabul, ... orang

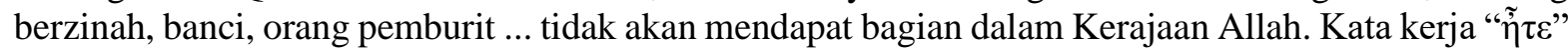

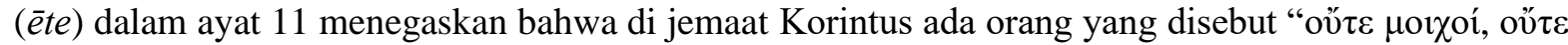

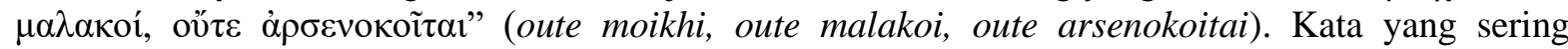

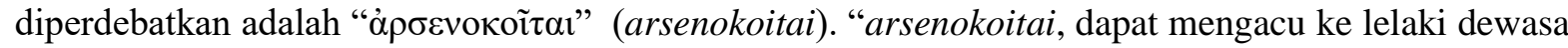
yang memiliki seorang budak yang dijadikan mitra seksualnya dalam melampiaskan nafsu syahwatnya, jadi jelas ini adalah dosa yang membutuhkan pelayanan gereja sebagai wujud kasih Kristus bahwa mereka membutuhkan Injil yang sejati yang menyelamatkan. Melalui diskusi ini saya menyerukan untuk kita kembali kepada Injil yang adalah kekuatan Allah yang menyelamatkan setiap orang yang percaya itu! Itulah Injil yang membuat para arsenokoitai memberi diri mereka disucikan dan menjadi orang-orang yang dikuduskan dan dibenarkan di dalam nama Tuhan Yesus Kristus.

Kata kunci: LGBTQ, Kehidupan Kristen, Teologi Kristen
\end{abstract}

\section{PENDAHULUAN}

LGBTQ bukanlah sebuah isu! LGBTQ bukan sekedar masalah yang dikedepankan untuk ditanggapi atau disikapi dengan jalan menjadi pro atau kontra, apalagi menganggap LGBTQ sebagai sebuah "desas-desus" atau kabar angin yang tidak jelas asal-usulnya. ${ }^{1}$ LGBTQ merupakan sebuah fenomena, yaitu fakta atau kenyataan yang nampak dalam masyarakat. ${ }^{2}$

Pada tahun 1973 The American Psychiatric Association (APA) mencabut homoseksualitas dari Diagnostic and Statistical Manual of Mental Disorder, sehingga posisi sebelumnya (1952) yang melihat homoseksualitas sebagai suatu penyakit mental dibatalkan. Pada tahun 1975, sikap tersebut diikuti oleh

${ }^{1}$ Dendy Sugono, Kamus Besar Bahasa Indonesia Pusat Bahasa, 4th ed. (Jakarta: Gramedia Pustaka Utama, 2011).552

${ }^{2}$ Ibid. 390 
The American Psychological Association (APA) dan The National Association of Social Workers (NASW) di Amerika Serikat. ${ }^{3}$ Di sisi lain, pada tanggal 17 Mei 1990 Organisasi Kesehatan Dunia (WHO) PBB juga telah mengambil posisi yang sama. Selanjutnya, berdasarkan beberapa pertimbangan penting yang diuraikan dalam sebuah kertas kerja Komisi HAM (HRC) PBB tanggal 24 September 2014, Komisi HAM PBB ini akhirnya pada tanggal 26 September 2014 memutuskan mendukung dan mengakui secara penuh HAM bagi kaum LGBT sebagai bagian dari "HAM yang universal".

Perkembangan ini diikuti dengan keputusan pada tanggal 26 Juni 2015 dimana Supreme Court Amerika Serikat memutuskan bahwa konstitusi Amerika menjamin pernikahan sesama jenis. ${ }^{5}$ Tak hanya itu, gereja-gereja juga mendukung keputusan tersebut sebagaimana terlihat dalam sikapnya yang turut mengesahkan pasangan suami-isteri sesama jenis dalam sebuah liturgi pemberkatan nikah. Ini adalah dampak logis ketika menerima keberadaan LGBT dalam konteks HAM. ${ }^{6}$ David Masci dan Michael Lipka mengungkapkan hasil penelitian Pew Research Center dalam artikelnya yang berjudul "Where Christian Churches, other religions stand on gay marriage", sebagai berikut:

Overall, a solid majority of white mainline Protestants (62\%) now favor allowing gays and lesbians to wed, with just 33\% opposed, according to a 2015 Pew Research Center survey. A similar share (63\%) say there is "no conflict" between their religious beliefs and homosexuality. ${ }^{7}$

Di Indonesia, melalui Persekutuan Gereja-Gereja di Indonesia (PGI) pada tanggal 17 Juni 2016 melayangkan surat Pengantar Pernyataan Sikap PGI perihal LGBT dan Pernyataan Pastoral tentang LGBT yang berisi 14 poin tertanggal 28 Mei 2016. Dalam Pernyataan Pastoral tentang LGBT tersebut ditegaskan bahwa:

Alkitab memang menyinggung fenomena LGBT, tetapi Alkitab tidak memberikan penilaian moral-etik terhadap keberadaan atau eksistensi mereka. Alkitab tidak mengeritisi orientasi seksual seseorang. Apa yang Alkitab kritisi adalah perilaku seksual yang jahat dan eksploitatif yang dilakukan oleh siapa pun...Gereja, sebagai sebuah persekutuan yang inklusif dan sebagai keluarga Allah, harus belajar menerima kaum LGBT sebagai bagian yang utuh dari persekutuan kita sebagai "Tubuh Kristus"... Gereja bukan saja harus menerima mereka, tetapi bahkan harus berjuang agar kaum LGBT bisa diterima dan diakui hak-haknya oleh masyarakat dan negara, terutama hak-hak untuk tidak didiskriminasi atau dikucilkan, perlindungan terhadap kekerasan, hak-hak untuk memperoleh pekerjaan, dan sebagainya. Para pemangku negara ini harus menjamin agar hak-hak asasi dan martabat kaum LGBT dihormati! Kaum LGBT harus diberikan kesempatan hidup dalam keadilan dan perdamaian. ${ }^{8}$

Di sini menjadi jelas bahwa mereka yang mendukung bukan tidak bertolak dari Alkitab. Mereka melakukan telaah terhadap ayat-ayat yang dijadikan dasar diskusi berkaitan dengan topik LGBT ini. Karena itu, hal ini bukanlah masalah menggunakan atau tidak menggunakan Alkitab melainkan persoalan hermeneutis. Selain persoalan hermeneutis, topik ini juga berkaitan dengan persoalan teologis. Michael L. Brown menunjukkan secara tepat dan jelas masalahnya lewat judul bukunya "Bisakah Anda Gay dan Kristen?" dan memaparkan pertanyaanya sebagai berikut:

Bisakah Anda menjadi gay, dan sekaligus Kristen? Jawaban kita terhadap pertanyaan ini sangat ditentukan oleh apa definisi kita terhadap istilah-istilah itu. Apakah "gay" hanya

\footnotetext{
${ }^{3}$ American Psychological Association, “Answers to Your Questions For a Better Understanding of Sexual Orientation \& Homosexuality,” Apa.Org (Washington: apa.org, 2002), last modified 2002, https://www.apa.org/topics/lgbt/orientation.pdf.

${ }^{4}$ Ibid.; United Nation General Assembly, "Follow-up to and Implementation of the Vienna Declaration and Programme of Ac," Outrightinternational.Org, last modified 2014,

https://www.outrightinternational.org/sites/default/files/HRC-27-L27-rev1.pdf; Pranoto Iskandar, Hukum HAM Internasional: Sebuah Pengantar Kontekstual (Cianjur: IMR Press, 2013).596-609

5 Saumi Rizqiyanto, "Alasan Amerika Melegalkan Pernikahan Sesama Jenis," Kompasiana, last modified 2015, http://www.kompasiana.com/saumiere/alasan-amerika-melegalkan-pernikahan-sesamajenis_55c1bd514f7a61de1839fde7.

${ }^{6}$ Ibid.; Iskandar, Hukum HAM Internasional: Sebuah Pengantar Kontekstual. 21

${ }^{7}$ DAVID MASCI and MICHAEL LIPKA, "Where Christian Churches, Other Religions Stand on Gay Marriage," Pewresearch.Org, last modified 2015, http://www.pewresearch.org/fact-tank/2015/12/21/wherechristian-churches-stand-on-gay-marriage/.

${ }^{8}$ Henriette Tabita Lebang, "Pernyataan Pastoral PGI Tentang LGBT," Pgi.or.Id.
} 
sekadar memiliki ketertarikan terhadap sesama jenis kelamin? Apakah "gay" itu berarti mempraktikkan homoseksualitas secara romantis dan seksual? Apakah itu artinya memiliki identitas "gay"? Dan apa yang dimaksud dengan "Kristen"? Apakah itu artinya pergi ke gereja? Dilahirkan kembali di dalam keluarga Kristen? Menjadi pengikut Yesus sejati?"

Target yang hendak dicapai melalui kegiatan pengabdian kepada masyarakat ini adalah edukasi yang konstruktif bagi gereja dalam melayani kaum LGBTQ, bagaimana penanganan atau terapi yang perlu dilakukan dan bagaimana sikap para pendeta maupun jemaat dalam menerima terlebih dahulu pribadi kaum LGBTQ bukan sebagai hakim dari sudut pandang iman Kristen. Sebagaimana yang sudah diuraikan di atas, solusi yang ditawarkan berkaitan dengan kegiatan tersebut adalah adanya pengenalan, pengetahuan, penerimaan dan motivasi bagi para pendeta dan jemaat untuk masa selanjutnya berkaitan dengan situasi yang dialami oleh kaum LGBTQ di sekitar mereka. Gereja tidak boleh mengasingkan mereka, sebaliknya harus merangkul. Ini adalah wujud kasih Kristen sebagaimana yang diajarkan oleh Kristus, dan hal yang bersifat pastoral.

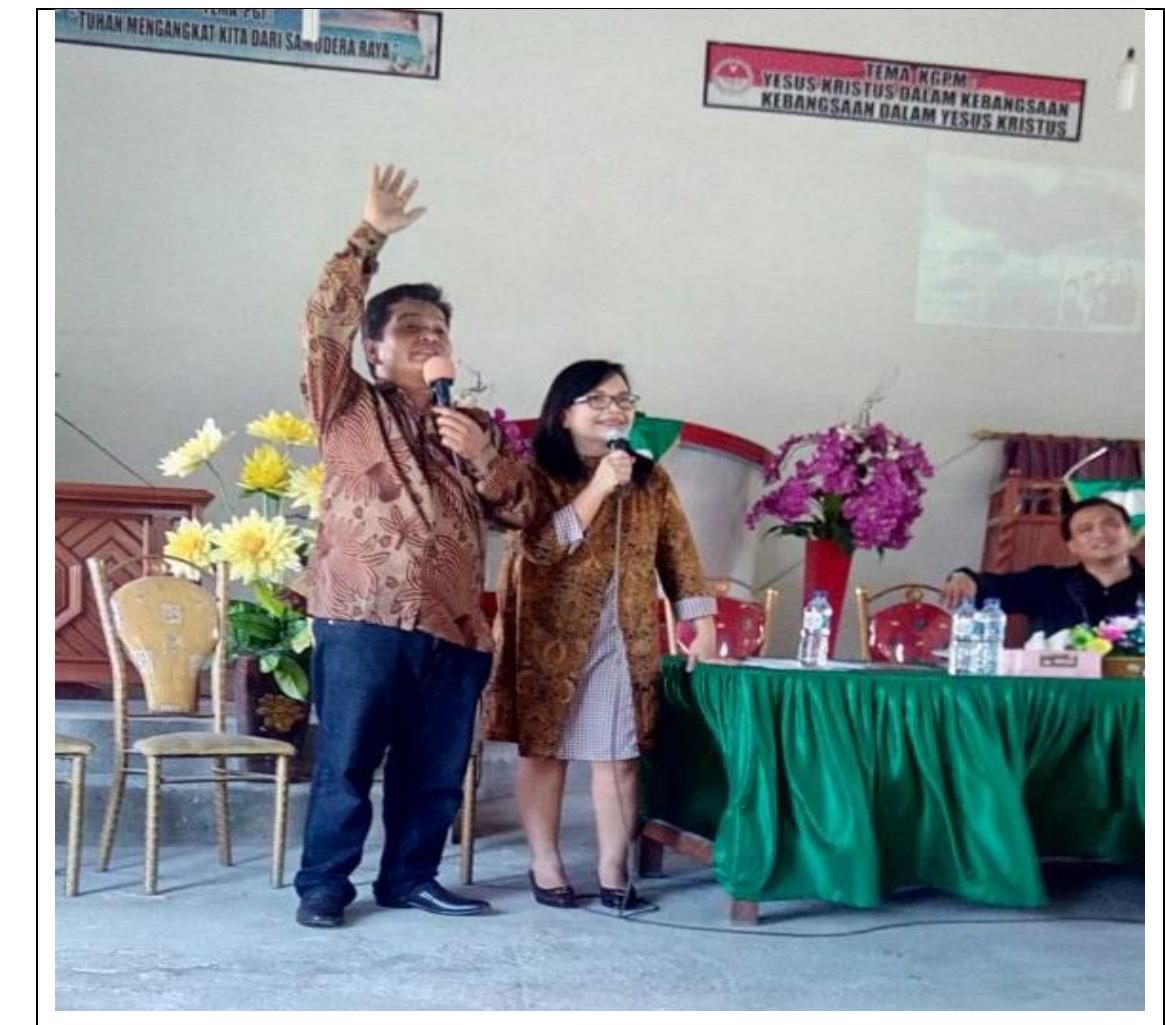

\section{Gambar 1. Pembukaan Kegiatan Edukasi Terhadap Fenomena LGBTQ Menurut Perspektif Teologi Kristen di KGPM Minahasa Selatan}

\section{METODE}

Tulisan ini disusun dengan menggunakan metode kualitatif dengan pendekatan studi fenomenologi tentang keberadaan kaum LGBTQ di masyarakat dengan mengkajinya secara mendalam melalui 1 Korintus 6:9-11 serta dengan mendiskursuskan hasil kajian tersebut dengan fenomena yang terjadi dalam kehidupan masyarakat yang terjadi dalam kegitan pengabdian masyarakat, sehingga diharapkan ada pengaruh kepada masyarakat dengan kehidupan masyarakat dengan segalah problematikanya, namun tetap taat pada aturan Firman Allah. Waktu kegiatan mulai dari perencanaan, persiapan, pelaksanaan hingga penyusunan laporan berlangsung mulai dari Agustus- November 2018.

\footnotetext{
${ }^{9}$ Michael L Brown, Bisakah Anda Gay Dan Kristen? (Jakarta: Nafiri Gabriel, 2016).xi
} 
Pelaksanaan kegiatan berupa sosialisasi CP dilaksanakan pada hari Jumat, 3 - 5 November 2018 berlokasi di di KGPM se wilayah Amurang Minahasa Selatan.

\section{HASIL DAN PEMBAHASAN}

\section{Dibenarkan Melalui Kristus}

Richard Davis dalam artikelnya "Justified Throught Faith" menyuguhkan doktrin pembenaran melalui iman sebagai pembelaan untuk menerima kaum LGBT. Ia menguraikan argumentasinya, sebagai berikut:

Are you made right with God by obeying all the laws in the Bible? Or is it by faith in Jesus' finished work on the Cross? Paul writes, "We maintain that a man is justified by faith apart from observing the law." (Romans 3:28) In the letter to the Galatians, Paul invites us to think back to the moment we first accepted Jesus as our Lord, "Did you receive the Spirit by observing the law, or by believing what you heard?" (Galatians 3:2b) Surely, it was while you yet had same-sex feelings that Jesus opened your heart to receive him and he saved you (Romans 5:8). Since God has saved you in Christ apart from considerations about your sexuality, will he now judge you on the basis of your sexuality? Not according to Paul, "For if, when we were God's enemies, we were reconciled to him through the death of his Son, how much more having been reconciled shall we be saved through his life! (Romans 5:10). You see, you won't find THE ANSWER chasing after this or that interpretation of Scripture because THE ANSWER is Jesus Christ, himself. By trusting in him and what he has done for you, you are saved from God's wrath (Romans 5:9). Or better yet, "God was reconciling the world to himself in Christ, not counting men's sins against them" (2 Corinthians 3:19), therefore, "we have peace with God through our Lord Jesus Christ, through whom we have gained access by faith into this grace in which we now stand." (Romans 5:1, 2). That's why anti-gay interpretations of Scripture can't condemn you but also gay-friendly interpretations can't justify you. "What then shall we say in response to this? If God is for us, who can be against us? He who did not spare his own Son, but gave him up for us all — how will he not also, along with him, graciously give us all things? Who will bring any charge against those whom God has chosen? It is God who justifies. Who is he that condemns?" (Romans 8:31-34) When you understand that it is God who justifies you in Jesus Christ then your faith and your hope will not rise and fall with the success or failure of this or that explanation of the "clobber" passages. ${ }^{10}$

Sekilas argumentasinya ini terlihat menarik dan masuk akal untuk menerima LGBT. Namun, segera menjadi jelas bagi kita bahwa Davis melupakan aspek perpalingan (iman dan pertobatan) dan pengudusan dalam konsep soteriologinya. Dalam diskusinya tentang argumentasi Paulus dalam kitab Roma di atas, ia melupakan apa yang dikatakan Paulus dalam Roma 12:1-2, "Karena itu, saudarasaudara, demi kemurahan Allah aku menasihatkan kamu, supaya kamu mempersembahkan tubuhmu sebagai persembahan yang hidup, yang kudus dan yang berkenan kepada Allah: itu adalah ibadahmu yang sejati. Janganlah kamu menjadi serupa dengan dunia ini, tetapi berubahlah oleh pembaharuan budimu, sehingga kamu dapat membedakan manakah kehendak Allah: apa yang baik, yang berkenan kepada Allah dan yang sempurna."

Cornelius Platinga, Jr. menyatakan bahwa dosa adalah sebuah penyimpangan, pencemaran dan disintegrasi. "Penyimpangan merupakan penyakit akhir-dan-maksud. Seperti yang secara luas dipahami, penyimpangan adalah pengalihan kesetiaan, tenaga, dan hasrat manusia dari Allah dan rencana Allah di dunia ini." 12 Penyimpangan ini kita bisa lihat dalam LGBT baik dalam orientasi maupun perilaku seksualnya serta redefinisi mereka tentang pernikahan beserta dengan tujuannya. Saya

\footnotetext{
${ }^{10}$ Richard Davis, "Justified Through Christ," Gaychurch.Org, http://www.gaychurch.org/homosexuality-and-the-bible/justified-through-christ/.

${ }^{11}$ Cornelius Platinga-Jr, Not the Way It's Supposed to Be: Sebuah Ikhtisar Populer Tentang Dosa (Surabaya: Momentum, 2004). 41-53

12 Ibid. 42
} 
tidak berkompeten untuk menjelaskan tentang perubahan kromosom atau persoalan genetika dalam diskusi tentang orientasi seksual. Namun, dalam kacamata Alkitab menjadi jelas bahwa hal itu adalah sebuah penyimpangan yang terjadi setelah dosa itu masuk dalam kehidupan manusia. ${ }^{13}$ Platinga menuturkan bahwa "Penyimpangan terkadang memiliki unsur pencemaran moral dan rohani, suatu dimensi lebih lanjut dari kerusakan." 14

Mencemari berarti mengotori (akar kata ini dalam Bahasa Latin berarti menyeret sesuatu menuju lumpur). Dalam tradisi Kristen, konsep pencemaran mengandung sisa-sisa konsep alkitabiah tentang kenajisan - pemikiran kuno dan misterius bahwa sebagian penyakit dan zat (misalnya, lepra, darah, air mani, dan bahkan jamur) memiliki kekuatan untuk mencemari dan membuat seseorang atau sesuatu tidak layak berdiri di hadapan Allah yang kudus dan sempurna. Dalam hal ini, kekudusan tidak hanya berarti sesuatu yang berbeda atau sesuatu yang transenden, tetapi juga suatu kepenuhan, kesatuan, dan kemurnian. Dalam dunia Timur Tengah kuno, keluarnya cairan tubuh menunjukkan hilangnya vitalitas, kehidupan dan keutuhan suatu pribadi. Demikian pula dengan perkawinan silang antar binatang dan antar tumbuh-tumbuhan. Dalam Imamat 19, kenajisan seremonial semacam ini dan kenajisan moral (penyembahan berhala, pemfitnah, penipuan) sama-sama menjadi contoh pencemaran. Gagasan yang ingin diungkapkan adalah bahwa dosa tidak hanya mencemari individu dan masyarakat tertentu tetapi juga menodai hubungan mereka dengan Allah. ${ }^{15}$

\section{Apakah Bisa Dipulihkan?}

Inilah pertanyaan yang masih hangat untuk didiskusikan. Mereka yang mengatakan tidak bisa memandang LGBT sebagai "keragaman yang diberikan Tuhan" - seperti titik tolak pemahaman dalam surat pastoral tentang LGBT yang dikeluarkan oleh PGI - sehingga kita tidak berhak untuk mengubah mereka menjadi orang lain. Mereka menegaskan bahwa kita harus menerima mereka apa adanya dan mengasihi mereka apa adanya. ${ }^{16}$ Mereka menuduh bahwa yang mengatakan "bisa" berarti menghakimi dan homofobia (takut dan benci terhadap kaum gay) sehingga mengakibatkan banyak anak muda LGBTQ yang mengakhiri hidupnya dengan melakukan bunuh diri. ${ }^{17}$

Apakah jawaban Alkitab tentang hal ini? Alkitab jelas mengatakan bahwa kita harus mengasihi "dengan perbuatan dan dalam kebenaran (1 Yohanes 3:18). Ketika seseorang "berbuat apa yang benar menurut pandangannya sendiri" dan tidak menurut Alkitab maka ia telah mengulang masa Hakimhakim (Hakim-Hakim 21:25). Sebagaimana ditegaskan dalam kitab Amsal, "Bila tidak ada wahyu, menjadi liarlah rakyat. Berbahagialah orang yang berpegang pada hukum (Amsal 29:18). Dan dalam 1 Korintus 6:9-11, Paulus menunjukkan bahwa LGBT bisa dipulihkan, "Atau tidak tahukah kamu, bahwa orang-orang yang tidak adil tidak akan mendapat bagian dalam Kerajaan Allah? Janganlah sesat! Orang cabul, penyembah berhala, orang berzinah, banci, orang pemburit, pencuri, orang kikir, pemabuk, pemfitnah dan penipu tidak akan mendapat bagian dalam Kerajaan Allah. Dan beberapa orang di antara kamu demikianlah dahulu. Tetapi kamu telah memberi dirimu disucikan, kamu telah dikuduskan, kamu telah dibenarkan dalam nama Tuhan Yesus Kristus dan dalam Roh Allah kita."

Kata kerja " $\tilde{\hat{\eta}} \tau \varepsilon$ " (ête) dalam ayat 11 menegaskan bahwa di antara jemaat Korintus ada orang-

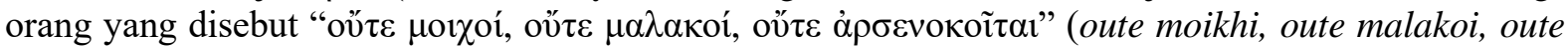

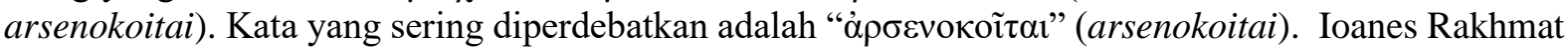
berpendapat bahwa:

"arsenokoitai, dapat mengacu ke lelaki dewasa yang memiliki seorang budak yang dijadikan mitra seksualnya pada saat si lelaki dewasa ini berhasrat melampiaskan nafsu syahwatnya.

\footnotetext{
${ }^{13}$ Ellen White, "Who Are the Nephilim?," Biblical Archaeology Society, last modified 2016, http://www.biblicalarchaeology.org/daily/biblical-topics/hebrew-bible/who-are-the-nephilim/.

${ }^{14}$ Platinga-Jr, Not the Way It's Supposed to Be: Sebuah Ikhtisar Populer Tentang Dosa. 45

${ }^{15}$ Ibid.46

${ }^{16}$ Brown, Bisakah Anda Gay Dan Kristen? 1-14

${ }^{17}$ Ibid. $15-49$
} 
Praktek seksual semacam ini, antara tuan dan budak lelaki, antara seorang pedofili dan korbannya, biasa dijumpai dalam dunia Yunani-Romawi pada era permulaan kekristenan."18

Dengan demikian istilah itu tidak menunjuk kepada kelompok LGBT. ${ }^{19}$ Benarkah demikian?.

Ensikopedia dari GLBTQ tentang St. Paul yang ditulis oleh Eugene Rice menguraikan arti kata arsenokoitai, sebagai berikut:

The word is a verbal noun, and its earliest attestation is in this verse of Paul's. It is a compound of arsen ="male" and koités = "a man who lies with (or beds)." And so we have, describing Oedipus, metrokoités, "aman who lies with his mother," doulokoités, "a man who lies with maidservants or female slaves, "polykoités, "a man who lies with many," and onokoités, "a man who lies with donkeys," said of Christians ina graffito from Carthage of about 195. Arsenokoitai are therefore "men who lie with males," and the Vulgate's masculorum concubitores (wheremasculorum is an objective genitive), renders the Greek exactly to mean "men who lie with males," "menwho sleep with males," "men who have sex with males." The source of arsenokoitai is in the Greek translation of the Hebrew Bible known as the Septuagint (finished around 130 B. C. E. for the use of Greek-speaking Jews). The Septuagint of Leviticus 18:22 reads:Kai meta arsenos ou koiméthés koitén gynaikeian, and of Lev. 20:13, Kai os an koiméthé meta arsenoskoitén gynaikos ... ;Englished we have, "With a male you shall not lie the bed/intercourse (koité) of awoman," and "Whoever lies with a male the koité of a woman, [both have done an abominable thing, theyshall be put to death.]" The dependence of Paul's arsenokoitai on the Levitical arsenos koitén demonstrates unequivocally itssource and confirms his intended meaning. The word was almost certainly coined by Greek-speaking Jews.Understood in the context of what we know about role playing in most ancient same-sex relationships,malakoi are the receptive parties and arsenokoitai the inserters in male-male anal intercourse. The bad news from the Christian Bible is that it condemns same-sex desire and same-sex acts withoutqualification of age, gender, role, status, consent, or membership in an ethnic community. ${ }^{20}$

Jadi, kelompok LGBT sendiri mengakui bahwa arsenokoite adalah istilah yang digunakan oleh Paulus untuk menunjuk pada para homoseksual. Itulah sebabnya, Rice menyimpulkan bahwa kabar buruk dari Alkitab adalah Alkitab mengutuk keinginan sex sama jenis dan aktifitas-aktifitas sex sama jenis tanpa kualifikasi usia, gender, peran, status, atau keanggotaan dalam sebuah komunitas etnis.

Namun, kabar baiknya adalah bahwa mereka, yaitu para arsenokoitai, bisa dipulihkan! Kalimat kedua dalam 1 Korintus 6: 11 menunjukkan akan hal ini, yaitu "Tetapi kamu telah memberi dirimu disucikan, kamu telah dikuduskan, kamu telah dibenarkan dalam nama Tuhan Yesus Kristus dan dalam Roh Allah kita."Kata penghubung “Tetapi” memberikan kontras tentang keberadaan para arsenokoitai dahulu atau sebelumnya dengan keberadaan mereka sekarang. Pemulihan itu dimulai dengan sikap mereka yang telah memberi diri mereka disucikan. ${ }^{21}$ Ini merupakan sikap yang menyatakan kesediaan untuk mengalami pembaharuan yang dikerjakan oleh Roh Kudus. ${ }^{22}$ Sebagaimana Roh Allah berperan aktif untuk mengubah kondisi chaos dalam penciptaan langit dan bumi (Kejadian1:2), demikian pula Roh yang sama berperan katif dalam penciptaan manusia baru di dalam Kristus (bdk. Titus 3:5).

${ }^{18}$ Ioanes Rakhmat, "LGBT, Agama, Teks Alkitab, Dan Pandangan Sains Modern,” Blogspot, last modified 2015, http://ioanesrakhmat.blogspot.co.id/2015/09/lgbt-agama-teks-alkitab-dan-pandangan.html.

${ }^{19}$ Robin Sroggs, The New Testament and Homosexuality (Philadelphia: Fortress, 1983).127

${ }^{20}$ Eugene Rice, "St. Paul," Glbtqarchive, http://www.glbtqarchive.com/sshindex.html.

${ }^{21}$ Daniel B Wallace, Greek Grammar Beyond the Basics (Grand Rapids: Zondervan Publishing House, 1996). 414,416-4125

22 Thomas R Schreiner, New Testament Theology: Memuliakan Allah Dalam Kristus (Yogyakarta: Penerbit Andi, 2015). 508 


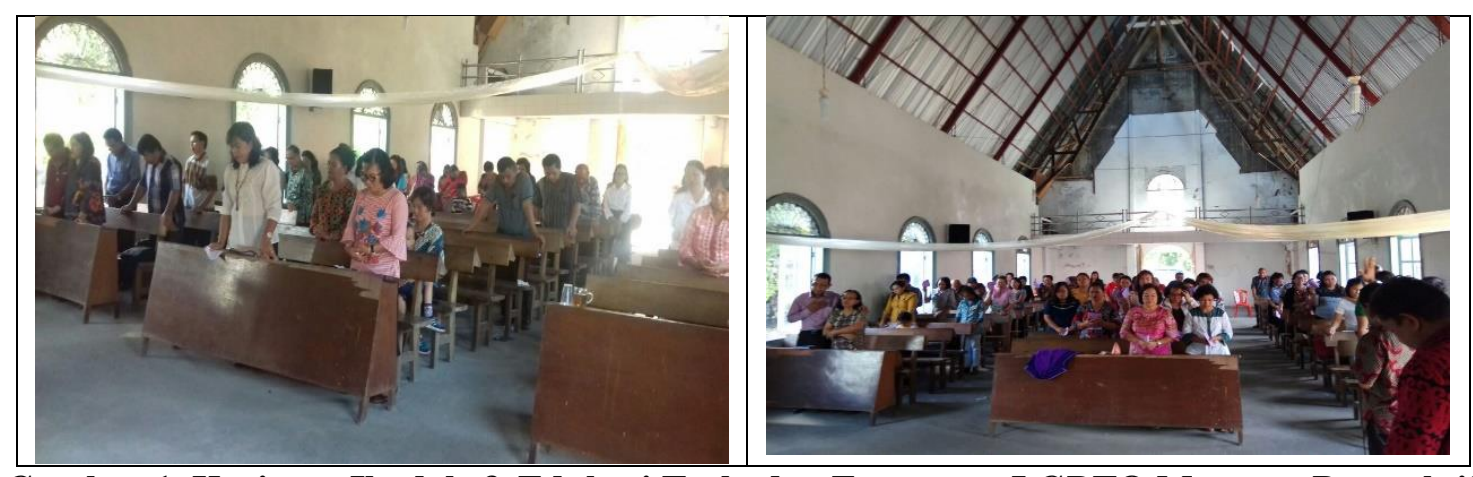

Gambar 1. Kegiatan Ibadah \& Edukasi Terhadap Fenomena LGBTQ Menurut Perspektif Teologi Kristen di KGPM Minahasa Selatan

\section{KESIMPULAN}

Arnold Tindas ${ }^{23}$ menyatakan bahwa kaum LGBTQ merupakan "manusia berdosa yang membutuhkan pelayanan." Gereja tidak boleh mengasingkan mereka, sebaliknya harus merangkul. Ini adalah wujud kasih Kristen sebagaimana yang diajarkan oleh Kristus, dan hal yang bersifat pastoral. Tetapi, bertolak dari pengamatan sedehana terhadap 1 Korintus 6:11 menyadarkan kita untuk semakin gencar dan merasakan penting akan kebutuhan akan Injil yang adalah "kekuatan Allah yang menyelamatkan setiap orang yang percaya" (Roma 1:16). Sebab, banyak pewartaan telah mengganti Injil yang sejati dengan "Injil kemakmuran", "Injil pelepasan dari resesi ekonomi”, "Injil kesembuhan dari segala penyakit" dan lain-lain. Melalui diskusi ini saya menyerukan untuk kita kembali kepada Injil yang adalah kekuatan Allah yang menyelamatkan setiap orang yang percaya itu! Itulah Injil yang diberitakan oleh Paulus, yang membuat para arsenokoitai memberi diri mereka disucikan dan menjadi orang-orang yang dikuduskan dan dibenarkan di dalam nama Tuhan Yesus Kristus dan dalam Roh Allah (1 Korintus 6:11).

\section{KEPUSTAKAAN}

Assembly, United Nation General. "Follow-up to and Implementation of the Vienna Declaration and Programme of Ac." Outrightinternational.Org. Last modified 2014. https://www.outrightinternational.org/sites/default/files/HRC-27-L27-rev1.pdf.

Association, American Psychological. "Answers to Your Questions For a Better Understanding of Sexual Orientation \& Homosexuality.” Apa.Org. Washington: apa.org, 2002. Last modified 2002. https://www.apa.org/topics/lgbt/orientation.pdf.

Brown, Michael L. Bisakah Anda Gay Dan Kristen? Jakarta: Nafiri Gabriel, 2016.

Davis, Richard. "Justified Through Christ." Gaychurch.Org. http://www.gaychurch.org/homosexuality-and-the-bible/justified-through-christ/.

Iskandar, Pranoto. Hukum HAM Internasional: Sebuah Pengantar Kontekstual. Cianjur: IMR Press, 2013.

Lebang, Henriette Tabita. "Pernyataan Pastoral PGI Tentang LGBT." Pgi.or.Id.

MASCI, DAVID, and MICHAEL LIPKA. "Where Christian Churches, Other Religions Stand on Gay Marriage." Pewresearch.Org. Last modified 2015. http://www.pewresearch.org/facttank/2015/12/21/where-christian-churches-stand-on-gay-marriage/.

Platinga-Jr, Cornelius. Not the Way It's Supposed to Be: Sebuah Ikhtisar Populer Tentang Dosa. Surabaya: Momentum, 2004.

Rakhmat, Ioanes. "LGBT, Agama, Teks Alkitab, Dan Pandangan Sains Modern." Blogspot. Last modified 2015. http://ioanesrakhmat.blogspot.co.id/2015/09/lgbt-agama-teks-alkitab-danpandangan.html.

Rice, Eugene. "St. Paul." Glbtqarchive. http://www.glbtqarchive.com/sshindex.html. Rizqiyanto, Saumi. "Alasan Amerika Melegalkan Pernikahan Sesama Jenis.” Kompasiana. Last

${ }^{23}$ Arnold Tindas, PERSPEKTIF TEOLOGI INJILI TERHADAP LGBT (Surabaya: SIMPOSIUM Teologi PASTI, 2016). 
modified 2015. http://www.kompasiana.com/saumiere/alasan-amerika-melegalkan-pernikahansesama-jenis_55c1bd514f7a61de1839fde7.

Schreiner, Thomas R. New Testament Theology: Memuliakan Allah Dalam Kristus. Yogyakarta: Penerbit Andi, 2015.

Sroggs, Robin. The New Testament and Homosexuality. Philadelphia: Fortress, 1983.

Sugono, Dendy. Kamus Besar Bahasa Indonesia Pusat Bahasa. 4th ed. Jakarta: Gramedia Pustaka Utama, 2011.

Tindas, Arnold. PERSPEKTIF TEOLOGI INJILI TERHADAP LGBT. Surabaya: SIMPOSIUM Teologi PASTI, 2016.

Wallace, Daniel B. Greek Grammar Beyond the Basics. Grand Rapids: Zondervan Publishing House, 1996.

White, Ellen. "Who Are the Nephilim?" Biblical Archaeology Society. Last modified 2016.

http://www.biblicalarchaeology.org/daily/biblical-topics/hebrew-bible/who-are-the-nephilim/. 